\title{
Effects of Vitamin D, K1, and K2 Supplementation on Bone Formation by Osteoblasts In Vitro: A Meta-analysis
}

\author{
Charlene E Lancaster and Rene E Harrison* \\ Department of Cell and Systems Biology and the Department of Biological Sciences, University of Toronto Scarborough, Toronto, Canada
}

\begin{abstract}
Bone loss is a major health problem that many aging individuals will face and thus research focusing on enhancing bone formation is of great importance. Cell biology or in vitro studies are particularly useful in exploring the exact effects a vitamin, supplement or drug has on particular processes within a certain cell type. Although there have been many cell biology articles focusing on the effects of vitamin $\mathrm{D}, \mathrm{K}_{1}$ or $\mathrm{K}_{2}$ addition on bone formation in vitro, there has yet to be a consensus amongst the literature. The purpose of this article is to determine the effects of vitamin $D, K_{1}$ and $K_{2}$ supplementation on osteoblast maturation parameters through meta-analysis of past cell biology literature. A Hedges $d$ effect size was calculated for each experiment extracted from past literature and the experiments were grouped by experiment and cell type. Homogeneity was assessed by the Cochran's $Q$ test, while the effect sizes' departure from zero was assessed by a $95 \%$ confidence interval and a non-directional test. Supplementation with vitamin $D, K_{1}$ and $K_{2}$ along with the combination of vitamin $\mathrm{K}_{2}+1$,25-dihydroxyvitamin $\mathrm{D}$, increased bone mineralization, while not consistently affecting all of the other parameters associated with bone formation. Vitamin $\mathrm{K}_{2}$ and $\mathrm{D}$ addition had variable effects on bone formation using different cell types, which calls into question the suitability of particular cell lines as models for clinical trials. Therefore, the conditions and parameters in which bone formation is studied in vitro must be considered carefully before running a vitamin supplementation or drug-testing experiment.
\end{abstract}

Keywords: Meta-analysis; Osteoblast; Vitamin K1; Vitamin K2; Vitamin D; Bone

Abbreviations: 1,25D: 1,25-Dihydroxyvitamin D; ALP: Alkaline Phosphatase; CI: Confidence Interval; df: Degrees of Freedom; DNA: Deoxyribonucleic Acid; $\bar{E}_{A L P}$ : Grand Mean Effect Size of ALP Activity Experiments; $\bar{E}_{C o l}$ : Grand Mean Effect Size of Collagen Levels Experiments; $\bar{E}_{D N A}$ : Grand Mean Effect Size of DNA Levels Experiments; $\bar{E}_{H C}$ : Grand Mean Effect Size of Human Cell Line Experiments; $\bar{E}_{H P}$ : Grand Mean Effect Size of Human Primary Cells Experiments; $\bar{E}_{m}$ : Overall Grand Mean Effect Size; $\bar{E}_{\text {Min }}$ : Grand Mean Effect Size of Murine Cell Line Experiments; $\bar{E}_{\text {Min }}$ : Grand Mean Effect Size of Mineralization Experiments; $\bar{E}_{M P}$ : Grand Mean Effect Size of Murine Primary Cells Experiments; $\bar{E}_{O C}$ : Grand Mean Effect Size of Osteocalcin Levels Experiments; $\bar{E}_{O P}$ : Grand Mean Effect Size of Osteopontin Levels Experiments; $\bar{E}_{O t}$ : Grand Mean Effect Size of Other Experiments; $\bar{E}_{p r}$ : Grand Mean Effect Size of Proliferation Experiments; NS: No Significance

\section{Introduction}

Bone is a strong, lightweight, highly dynamic connective tissue that owes its strength to the calcified extracellular matrix produced by osteoblasts. Osteoblasts make and secrete large quantities of collagen that organize to form a fibrillar network, together with other extracellular proteins (i.e. osteocalcin [1]). Osteoblasts also play a role in the deposition of minerals, in the form of hydroxyapatite crystals composed of calcium hydroxyphosphate. The maturation of osteoblasts depends on two processes: proliferation and differentiation. Proliferation is an important component of the maturation of osteoblasts, since osteoblast differentiation and mineralization only occurs after the cells reach confluence [2,3]. Cell-cell contacts induce osteoblast differentiation in high confluence, ascorbic acid (AA)treated cultures [4]. Different stages of osteoblast differentiation can be characterized by the expression of certain genes [5]. Early differentiation is defined by the expression of high levels of the enzyme alkaline phosphatase (ALP), while late differentiation is characterized by the expression of osteopontin and osteocalcin [5].
Given the prevalence of osteoporosis, studies looking at ways to enhance bone formation and/or diminish bone resorption are of high importance. Previously, vitamins $\mathrm{D}, \mathrm{K}_{1}$ and $\mathrm{K}_{2}$ have been investigated as possible bone formation-enhancing supplements [6]. Vitamin D is found in two major forms: $\mathrm{D}_{2}$, which is obtained from the ingestion of plants and fungi, and $\mathrm{D}_{3}$, which is both synthesized in the skin and obtained through the consumption of other animals [7]. Both vitamin $\mathrm{D}_{2}$ and $\mathrm{D}_{3}$ are first hydroxylated in the liver to form 25-hydroxyvitamin $\mathrm{D}$ (25D), which is the major circulating form of vitamin $\mathrm{D}$ [8]. The second hydroxylation event occurs in the kidneys resulting in the formation of 1,25-dihydroxyvitamin $\mathrm{D}(1,25 \mathrm{D})$, which is the active form of vitamin D [8]. Although only 1,25D is active, $1,25 \mathrm{D}, 25 \mathrm{D}$ and vitamin $\mathrm{D}$ (the prohormone) can diffuse freely through the plasma membrane of cells [9].Vitamin D enters the nucleus of osteoblasts and binds to the vitamin $\mathrm{D}$ receptor [6]. This complex subsequently binds to deoxyribonucleic acid (DNA) sequences, which modulate the transcription of certain genes to stimulate the production of proteins that are critical for bone mineralization [6]. There are two natural forms of vitamin $\mathrm{K}$ : vitamin $\mathrm{K}_{1}$ and vitamin $\mathrm{K}_{2}$. Vitamin $\mathrm{K}_{1}$ is synthesized by plants, while vitamin $K_{2}$ is produced by bacteria [10]. Vitamin $K_{2}$ is also synthesized in certain vertebrate tissue through the conversion of vitamin $\mathrm{K}_{1}$ or phylloquinone into menaquinone- 4 , a form of vitamin $\mathrm{K}_{2}$, using the enzyme UbiA prenyltransferase containing 1 (UBIAD1; [11]). Vitamin $\mathrm{K}$ functions as a cofactor for the enzyme gammacarboxylase, which carboxylates glutamic acid and results in its

*Corresponding author: Harrison RE, Department of Biological Sciences, University of Toronto Scarborough, Toronto, Ontario, Canada, Tel: 01416 2877377; Fax: 01416 287-7676; E-mail: harrison@utsc.utoronto.ca

Received July 07, 2017; Accepted August 25, 2017; Published August 31, 2017 Citation: Lancaster CE, Harrison RE (2017) Effects of Vitamin D, $\mathrm{K}_{1}$, and $\mathrm{K}_{2}$ Supplementation on Bone Formation by Osteoblasts In Vitro: A Meta-analysis. J Biom Biostat 8: 365. doi: 10.4172/2155-6180.1000365

Copyright: (c) 2017 Lancaster CE, et al. This is an open-access article distributed under the terms of the Creative Commons Attribution License, which permits unrestricted use, distribution, and reproduction in any medium, provided the original author and source are credited. 
conversion to gamma-carboxyglutamic acid [10]. Osteocalcin, which is a protein essential for the formation of hydroxyapaptite crystals, requires the gamma-carboxylation of three glutamic acid residues in order to bind calcium [10].

Experiments that are performed in vitro allow one to test the effects, safety and efficacy of particular supplements or drugs on cells in a controlled environment and thus cell culture studies are commonly run as a precursor to clinical trials. Although cell culture can ignore the interactions between different tissues within the body, which may influence the phenomenon of interest, in vitro experiments are still an invaluable tool to dissect in detail an event of interest. Despite the many clinical studies looking at the effects of vitamin supplementation on bone, in vitro vitamin supplementation studies allow one to easily explore the exact bone formation parameters that are influenced by each of the vitamins.

Although many studies have looked at the effects of vitamin $\mathrm{K}_{1}$, $\mathrm{D}$ and/or $\mathrm{K}_{2}$ supplementation on in vitro osteoblast maturation parameters, including mineralization and ALP activity, the results of past articles failed to consistently agree with one another. We decided to resolve this conflict by performing several meta-analyses on the published cell biology literature. Meta-analysis is an quantitative analysis procedure that is used to mathematically combine results from previous research articles to make conclusions regarding that field of study [12,13]. Meta-analyses are commonly used in medical research in order to make decisions regarding treatment when results of the previous literature are diverse and conflicting [12]. In addition, the field of ecology readily uses meta-analyses, to explore heterogeneity, identify patterns and allow researchers to make decisions using the pooled data, all of which would not be possible using individual studies [14]. Just like in the medical and ecological fields, meta-analyses could be used in the cell biology field to determine the overall effect of a treatment on certain cells, when the previous literature is diverse and conflicting. In addition, the use of meta-analysis in basic research could help improve reproducibility of experiments, as well as it could identify and correct for potentially confounding variables, which could be the cause of the variability within the literature [15]. Thus, we performed several metaanalyses to conclusively determine the effect of vitamin $\mathrm{D}, \mathrm{K}_{1}, \mathrm{~K}_{2}$ and the combination of $\mathrm{K}_{2}+\mathrm{D}$ on several bone formation parameters in different types of osteoblasts (i.e. cell lines vs. primary cells).

\section{Methods}

\section{Literature survey and data extraction}

An extensive literature search was employed to find cell biology publications that examined the effect of vitamin $\mathrm{D}, \mathrm{K}_{1}$ and/or $\mathrm{K}_{2}$ supplementation on osteoblast maturation parameters. We searched both PubMed and Summon databases using different combinations of the keywords: osteoblast, bone, vitamin $\mathrm{K}$, vitamin $\mathrm{D}$, mineralization, differentiation, vitamin $\mathrm{K}_{1}$, vitamin $\mathrm{K}_{2}$, menaquinone, phylloquinone, 1,25-dihydroxyvitamin $\mathrm{D}(1,25 \mathrm{D})$ and 25 -hydroxyvitamin $\mathrm{D}$ (25D). The process used to choose papers for the meta-analyses was outlined in Figure 1. Briefly, a total of 22 cell biology articles were included in the meta-analyses and contained a total of 275 experiments [16-37]. These experiments were sorted into separate meta-analyses depending on the type of vitamin(s) supplemented. The vitamin $\mathrm{K}_{2}$ experiments that were included within the meta-analysis either supplemented cells with menaquinone- 4 or menaquinone-7, where both are forms of vitamin $\mathrm{K}_{2}$. In addition, the vitamin D meta-analysis included experiments that utilized the $25 \mathrm{D}$ or $1,25 \mathrm{D}$ form of vitamin $\mathrm{D}_{2}$ or vitamin $\mathrm{D}_{3}$. For the studies where quantitative data was not available, the program Plot Digitizer (version 2.6.6, http://plotdigitizer.sourceforge.net/) was used to extract the information from the figures. When only mineralization images were included in a paper without quantification, the program ImageJ (version 1.46r, http://imagej.nih.gov/ij/) was used to estimate the amount of mineralization based on intensity of the stain. All of the experiments included some measure of variation (i.e. standard deviation) and the number of replicates used to produce the mean measurement. The studies that qualified for our meta-analyses are listed.

\section{Statistical analysis}

The statistical approach and the equations used are adapted from

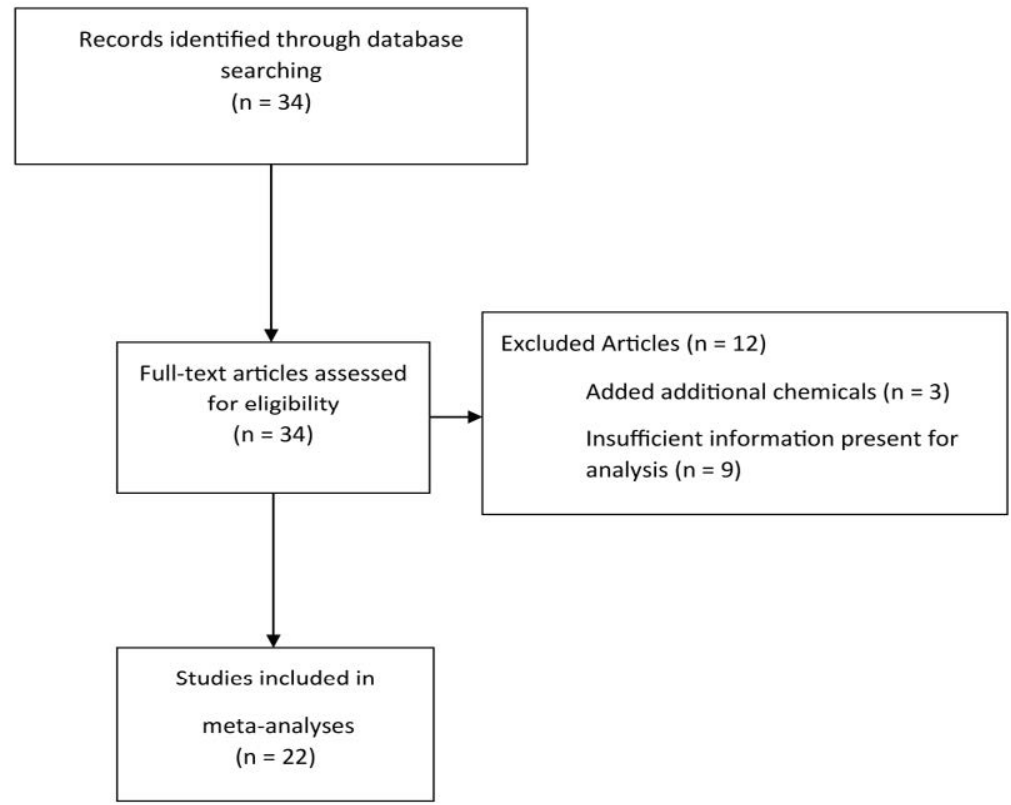

Figure 1: Flow diagram showing the criteria for cell biology article selection for the meta-analyses. 
Gurevitch, Curtis and Jones [38]. Meta-analysis allows one to determine the overall effect size of a phenomenon by compiling the results of the related independent studies. In this case the phenomenon that was characterized was the effect of vitamin $\mathrm{D}, \mathrm{K}_{1}$ or $\mathrm{K}_{2}$ on osteoblast maturation. For each experiment, a Hedges' $d$ value was calculated to determine the effect size in terms of an unbiased standardized mean difference between a vitamin treated and untreated group. In most cases, with the exception of measures of cytotoxicity and apoptosis (where a decrease in value indicates greater osteoblast survival), the mean control values were subtracted from the mean treatment values. A positive effect size thus indicated that vitamin addition increased a parameter of osteoblast maturation (i.e. amount of mineralization). Individual experiment effects were then combined into a grand mean effect. Subanalysis was used to further break the data into smaller groups to assess the effect of the vitamins on a specific osteoblast maturation parameter or cell type.

Homogeneity of the experiments analyzed in the meta-analysis increases the confidence that the overall grand mean represents any study looking at the same phenomenon. In order to assess the homogeneity of the treatment responses, Cochran's $Q$ test was utilized, where $\mathrm{p}<0.050$ was considered significant. If the effects were considered homogeneous (Cochran's $Q$ was not significant), a fixed-effects model was used to calculate the grand mean effect. However, if the effects were considered heterogeneous, a mixed-effects model was utilized to calculate the grand mean effect. A mixed-effects model differs from that of a fixed-effects model in that it incorporates an estimate of between experiment variance. If the mixed-effects model was used, a final Cochran's $Q$ test was employed to determine the homogeneity of this model.

For each grand mean effect and Hedges' $d$ a 95\% confidence interval (CI) was constructed and observed as to whether it intersected zero, as this would indicate that the effect size is not significantly different than zero. As another assessment of the effects' difference from zero, a nondirectional test, similar to a $X^{2}$ test was employed as an independent estimate of the $p$-values (where $p<0.050$ indicated significance). In this test, either the variances or adjusted variances were used depending on if a fixed or mixed model was utilized to calculate the grand mean.

\section{Results}

\section{Meta-analyses overview}

We were interested in how vitamin supplementation influences bone health and began our study with a survey of the cell biology literature that tested the effects of vitamins on bone formation by osteoblasts. After an exhaustive search, peer-reviewed articles were chosen that tested the effects of vitamins $\mathrm{K}_{1}, \mathrm{~K}_{2}, \mathrm{D}$ and combinations of vitamins on osteoblast bone formation. Importantly, these reports contained all the information (i.e. number of replicates) that is required for article inclusion in a meta-analysis. The final journal articles chosen are listed in Supplemental Table 1. A meta-analysis was then performed using the methodology adapted from Gurevitch, Curtis and Jones [38] for each of the vitamins and for the experiments from a single study that used a combination of vitamins, where their effect on bone formation was investigated.

Two separate subanalyses on the same experiments were performed within the meta-analyses based on: 1) type of experiment performed and 2) cell type examined. The experiments in the vitamin $\mathrm{K}_{2}$, vitamin $\mathrm{D}$, vitamin $\mathrm{K}_{1}$ and $\mathrm{K}_{2}+1,25 \mathrm{D}$ (where 1,25-dihydroxyvitamin $\mathrm{D}$ or $1,25 \mathrm{D}$ is a form of vitamin D) meta-analyses underwent 'experiment

\begin{tabular}{|c|c|c|c|}
\hline & $\mathbf{k}^{1}$ & $Q_{f}$ & $\mathbf{Q}_{\mathbf{m}}{ }^{2}$ \\
\hline Vitamin $\mathrm{K}_{1}$ & 27 & $123^{*}$ & $44.7^{*}$ \\
\hline Mineralization & 15 & $65.3^{*}$ & $20.4 \mathrm{NS}$ \\
\hline ALP Activity & 7 & $16.3^{*}$ & $6.43 \mathrm{NS}$ \\
\hline Other Experiments & 5 & $39.8^{*}$ & $5.45 \mathrm{NS}$ \\
\hline Vitamin $\mathrm{K}_{2}$ & 98 & $567^{*}$ & $168^{*}$ \\
\hline Mineralization & 29 & $139^{*}$ & $42.3^{*}$ \\
\hline ALP Activity & 33 & $151^{*}$ & 41.6 NS \\
\hline Proliferation & 10 & $32.5^{\star}$ & $9.42 \mathrm{NS}$ \\
\hline DNA Levels & 11 & $17.3 \mathrm{NS}$ & $\cdots$ \\
\hline Osteocalcin Levels & 6 & $28.9^{*}$ & $6.14 \mathrm{NS}$ \\
\hline Other Experiments & 9 & $49.5^{\star}$ & $13.1 \mathrm{NS}$ \\
\hline Vitamin D & 128 & $652^{*}$ & $311^{*}$ \\
\hline Mineralization & 29 & $183^{*}$ & $80.0^{*}$ \\
\hline ALP Activity & 28 & $60.2^{*}$ & $32.1 \mathrm{NS}$ \\
\hline Osteocalcin Levels & 18 & $120^{*}$ & $52.1^{*}$ \\
\hline Collagen Levels & 31 & $132^{*}$ & $61.4^{*}$ \\
\hline Osteopontin Levels & 10 & $33.9^{*}$ & $21.0^{*}$ \\
\hline Other Experiments & 12 & $13.2 \mathrm{NS}$ & $\cdots$ \\
\hline$K_{2}+1,25 D$ Compared to $K_{2}$ Alone & 11 & $28.8^{*}$ & 10.9 NS \\
\hline Mineralization & 6 & $16.7^{*}$ & $4.94 \mathrm{NS}$ \\
\hline Other Experiments & 5 & $10.1^{*}$ & $3.71 \mathrm{NS}$ \\
\hline $\mathrm{K}_{2}+1,25 \mathrm{D}$ Compared to $1,25 \mathrm{D}$ Alone & 11 & $62.3^{*}$ & $11.7 \mathrm{NS}$ \\
\hline Mineralization & 6 & $3.56 \mathrm{NS}$ & $\cdots$ \\
\hline Other Experiments & 5 & $37.3^{*}$ & $5.78 \mathrm{NS}$ \\
\hline
\end{tabular}

${ }^{1}$ Cochran's $Q$ tests were used to determine the homogeneity of the treatment responses from $\mathrm{k}$ \# of experiments.

${ }^{*} p<0.050$ indicates responses are heterogeneous and NS (no significance) indicates responses are homogeneous.

${ }^{2}$ The homogeneity of the mixed-effects model was only determined if the fixedeffects model was considered heterogeneous $(p<0.050)$.

Table 1: The homogeneity test results for the fixed-effects $\left(Q_{\mathrm{f}}\right)$ and mixed-effects $\left(Q_{m}\right)$ models of each vitamin meta-analysis, where the meta-analyses are grouped by type of experiment.

type' subanalysis by grouping them into subgroups relating to the type of experiment employed to quantitate bone formation. Unfortunately, only the experiments in the vitamin $\mathrm{K}_{2}$ and $\mathrm{D}$ meta-analyses were categorized by 'cell type' because there were an insufficient number of experiments within each of the cell type groups for the vitamin $\mathrm{K}_{1}$ and $\mathrm{K}_{2}+1,25 \mathrm{D}$ meta-analyses. The results of the homogeneity test for each meta-analysis were summarized into two tables (more detail to come in the following section), depending on if they were grouped by experiment or cell type. In addition, the effect of each vitamin or combination of vitamins on bone formation (measured as effect size) in different cell types was displayed graphically in several figures. Each figure contained the experiment or cell type classified meta-analysis of one vitamin or combination of vitamins (described later).

\section{Homogeneity within the meta-analyses that were grouped by the type of experiment}

In order to choose the model to calculate the grand mean effect sizes (the average of effect sizes in that group) for each subgroup as well as the overall grand mean, the homogeneity of the experiments used in each meta-analysis was tested (Table 1). Homogeneity of the experimental results included in the meta-analysis increases the confidence that the overall grand mean will represent any study looking at the same phenomenon. If the experiments were found to be homogeneous using the fixed-effects model (i.e. the test was not significant), then the fixed-effects model was used to calculate the overall grand mean effect size. However, if the homogeneity test using 
the fixed-effects model was significant (indicating heterogeneity), the mixed-effects model was used to calculate the grand mean.

The experiments used in the vitamin $\mathrm{K}_{1}, \mathrm{~K}_{2}, \mathrm{D}$ and $\mathrm{K}_{2}+1,25 \mathrm{D}$ metaanalyses, before subanalysis (in bold in Table 1), were heterogeneous using the fixed model and thus the mixed-effects model was used to calculate the overall grand mean effect sizes. Only the experiments used for the combination of $\mathrm{K}_{2}+1,25 \mathrm{D}$ meta-analyses were homogeneous when using the mixed-effects model, which suggested that the experiments within the other meta-analyses should be sorted into smaller, more homogeneous groups.

To observe the effect of the vitamin supplementation (alone or in combination) on the experiment types utilized to assay bone formation, the experiments within the meta-analyses were first categorized by type of experiment (Table 1). For the vitamin D meta-analysis most of the experiment type groups were heterogeneous and thus the mixed-effects model was used to calculate the grand mean for each group. However, for the majority of the groups within the vitamin D meta-analysis, the mixed model was still not homogeneous. Unlike the vitamin D metaanalysis, the vitamin $\mathrm{K}_{1}$ experiment groups were all heterogeneous using the fixed-effects model and the grand means were determined using the mixed model (Table 1). In this case however, the majority of experiment groups were considered homogeneous using the mixed model. Most of the grand means calculated for each experiment type group for the vitamin $\mathrm{K}_{2}$ meta-analysis used the mixed-effects model and the majority of the experiments within the groups were considered homogeneous using this model. In contrast to the other meta-analyses, where a control untreated group was compared to a vitamin treatment group, the $\mathrm{K}_{2}+1,25 \mathrm{D}$ data was used to run two meta-analyses. In this first meta-analysis the combination group was considered the treated group and the group where only vitamin $\mathrm{K}_{2}$ was added was the control group, while in the second meta-analysis the group supplemented with only $1,25 \mathrm{D}$ was considered the control group. It should be noted that all the experiments used for the combination meta-analyses originated from the same paper [17]. In the $\mathrm{K}_{2}+1,25 \mathrm{D}$ compared to $\mathrm{K}_{2}$ alone metaanalysis, the data was heterogeneous within both of the experiment groups, which indicated that a mixed-effects model was required to calculate the grand mean effect sizes (Table 1). The use of the mixed model also resulted in homogeneity within the groups. The experiment type group called Mineralization within the $\mathrm{K}_{2}+1,25 \mathrm{D}$ compared to $1,25 \mathrm{D}$ alone meta-analysis was homogeneous, while the Other Experiments group was heterogeneous using a fixed-effects model and thus the fixed and mixed models were used to calculate the grand means, respectively. Homogeneity was obtained in the group called Other Experiments through the use of the mixed effects model.

Vitamin $\mathrm{K}_{1}, \mathrm{~K}_{2}, \mathrm{D}$ and $\mathrm{K}_{2}+1,25 \mathrm{D}$ meta-analyses had significantly positive overall grand mean effect sizes and most of the experiment type grand mean effect sizes were significantly greater than zero.

Within the graphical representations of the meta-analyses that were grouped by type of experiment (Figures 2-5), each unlabelled bar represents a single experiment extracted from one of the papers listed within Supplemental Table 1. For each of the experiments, effect sizes were calculated and the measurement indicated if the vitamin(s) changed a parameter of osteoblast maturation, including mineralization and osteocalcin levels, compared to an untreated group. The overall effect of the vitamin(s) on osteoblast maturation parameters was determined by calculating the overall grand mean effect size (bar labelled $\bar{E}_{m}$ in Figures 2-5). Additionally, the experiments were sorted into experiment type subgroups and shade-coded according to these groups. The grand mean of each subgroup was used to determine the effect of the vitamin(s) on particular osteoblast maturation characteristics (bars labelled $\bar{E}$ and a short form for each experiment name in Figures 2-5.

Within the vitamin $K_{1}$ meta-analysis, the experiments were grouped into the following subgroups: Mineralization (included calcium and phosphorus levels), ALP Activity and Other Experiments

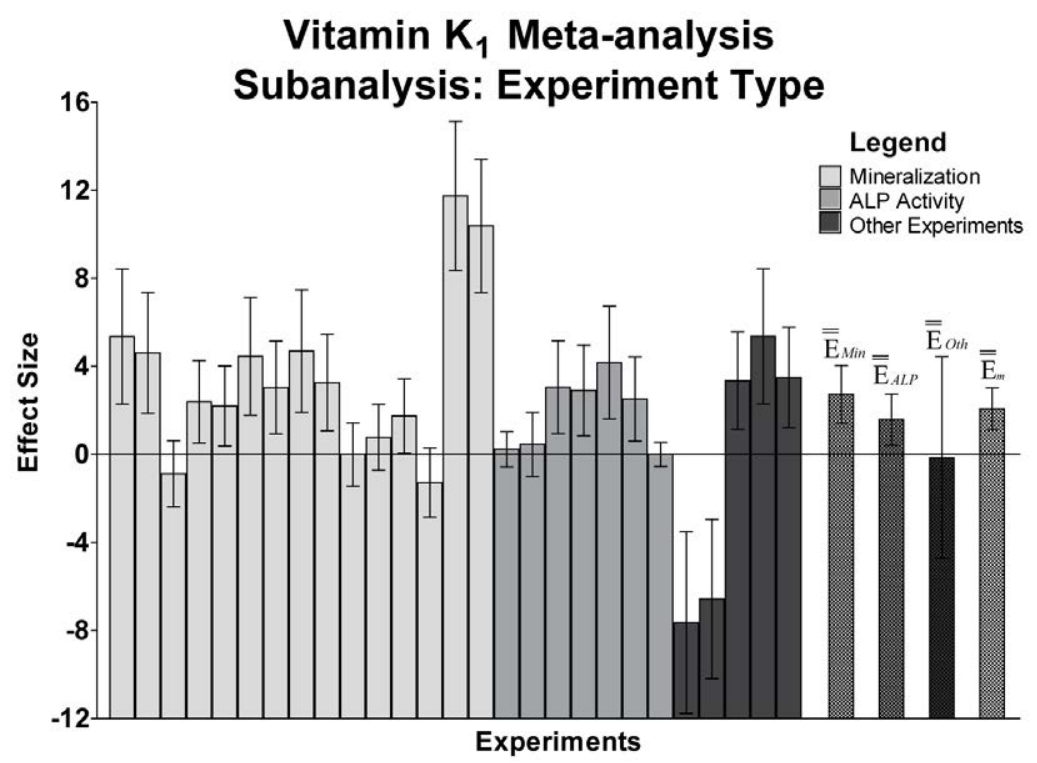

In the graph displaying the vitamin $\mathrm{K}_{1}$ meta-analysis that was grouped by experiment type, each unlabelled bar represents the effect size of an experiment, as measured using the Hedges' $d$ method. The bars were shaded according to experiment type and the error bars represent $95 \%$ confidence intervals. The grand means for each experiment type is signified by $\bar{E}$ and a short form for each experiment name and the overall grand mean is signified by $\bar{E}_{m}$. The experiments used in the vitamin $\mathrm{K}_{1}$ meta-analysis were extracted from 5 articles.

Figure 2: The vitamin $\mathrm{K}_{1}$ meta-analysis had an overall grand mean effect size that was significantly greater than zero and most of the experiment type grand mean effect sizes were significantly positive. 


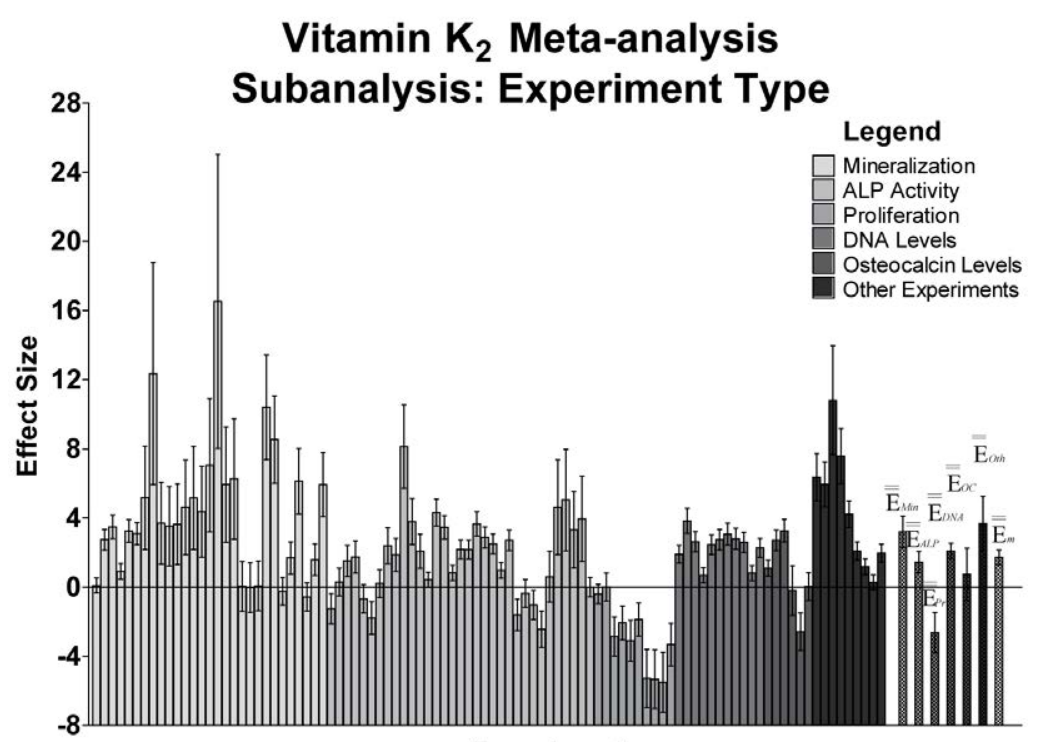

Experiments

In the graph displaying the vitamin $\mathrm{K}_{1}$ meta-analysis that was grouped by experiment type, each unlabelled bar represents the effect size of an experiment, as measured using the Hedges' $d$ method. The bars were shaded according to experiment type and the error bars represent $95 \%$ confidence intervals. The grand means for each experiment type is signified by $\bar{E}$ and a short form for each experiment name and the overall grand mean is signified by $\bar{E}_{m}$. The experiments used in the vitamin $\mathrm{K}_{2}$ meta-analysis were extracted from 8 articles.

Figure 3: The vitamin $\mathrm{K}_{2}$ meta-analysis revealed a significantly positive overall grand mean effect size and the majority of the experiment type grand means were significantly greater than zero.

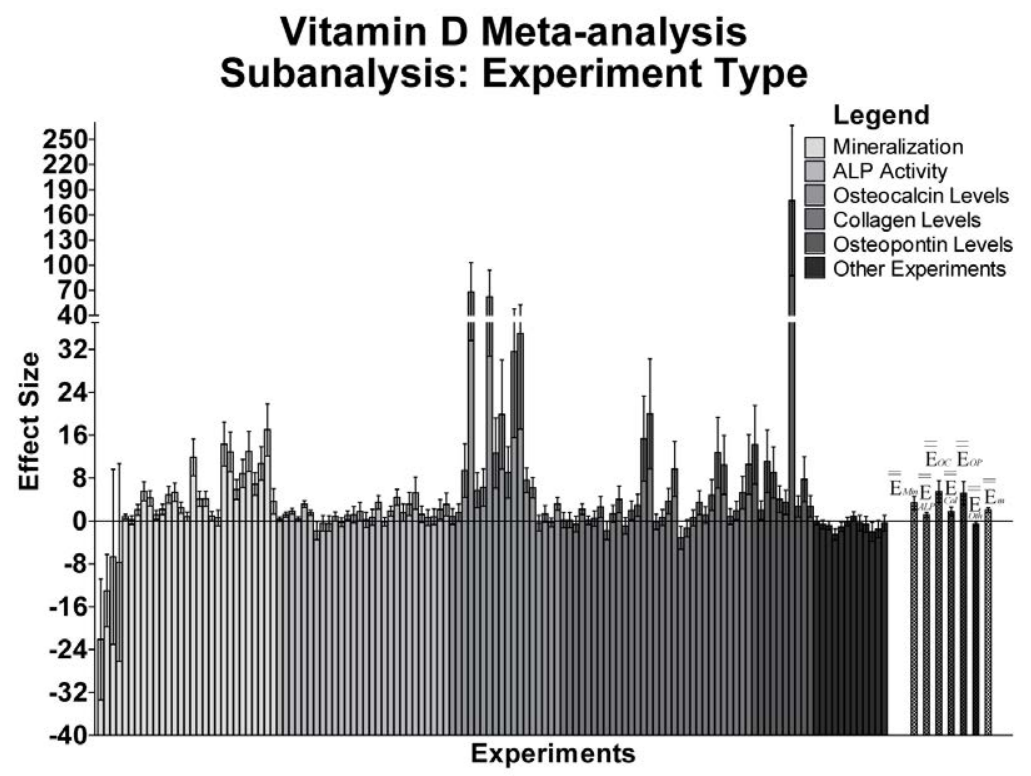

In the graph displaying the vitamin $\mathrm{K}_{1}$ meta-analysis that was grouped by experiment type, each unlabelled bar represents the effect size of an experiment, as measured using the Hedges' $d$ method. The bars were shaded according to experiment type and the error bars represent $95 \%$ confidence intervals. The grand means for each experiment type is signified by $\bar{E}$ and a short form for each experiment name and the overall grand mean is signified by $\bar{E}_{m}$. The experiments used in the vitamin D meta-analysis were extracted from 15 articles.

Figure 4: The vitamin D meta-analysis had an overall grand mean effect size that was significantly greater than zero and most of the experiment type grand mean effect sizes were significantly positive.

(Figure 2), where Other Experiments contained experiment types that did not have enough experiments $(\mathrm{k})$ to have their own group. The effect sizes of the majority of experiments analyzed within the vitamin $\mathrm{K}_{1}$ meta-analysis were positive with confidence intervals (CIs) that did not intersect zero, which indicated that these effect sizes were significantly greater than zero. This trend was mirrored when looking at the overall grand mean, which suggested that the addition of vitamin $\mathrm{K}_{1}$ significantly and positively increased osteoblast maturation parameters. A non-directional test also indicated significance for the overall grand mean's departure from zero $\left(X^{2}=62.9, d f=27, p=0.0001\right)$, which agreed with the CI test (Figure 2). The grand mean effects of the Mineralization and ALP Activity experiment groups were also positive 

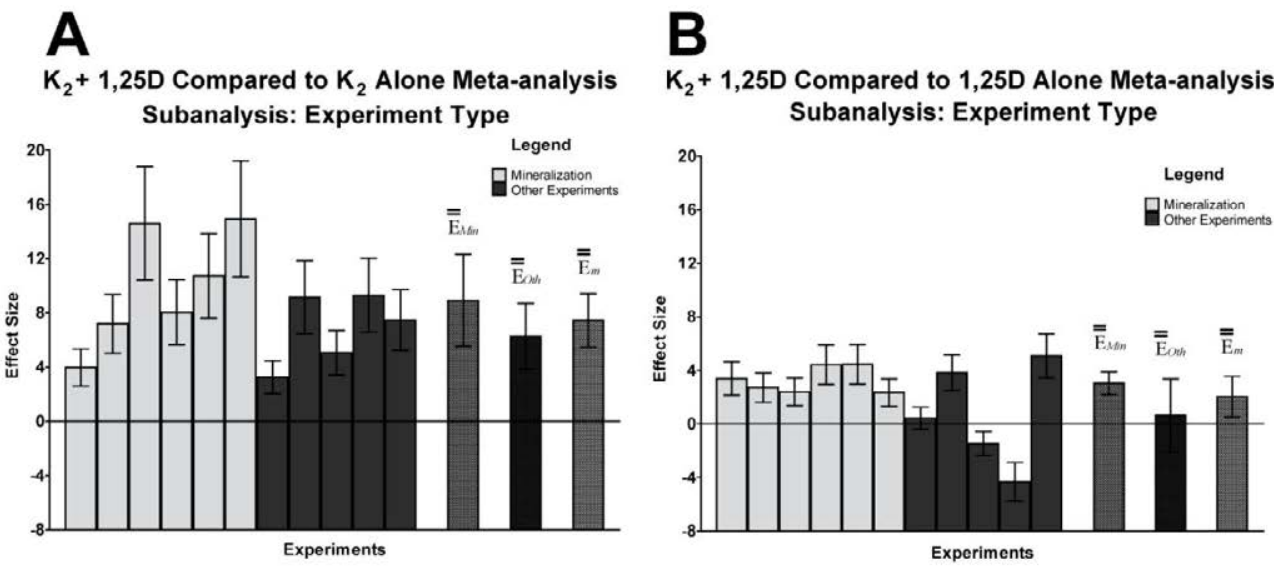

In the graph displaying the experiment type grouped meta-analyses for $K_{2}+1,25 \mathrm{D}$ compared to $(A)$ vitamin $K_{2}$ alone and (B) $1,25 \mathrm{D}$ alone, each unlabelled bar represents the effect size of an experiment, as measured using the Hedges' $d$ method. The bars were shaded according to experiment type and the error bars represent $95 \%$ confidence intervals. The grand means for each experiment type is signified by $\bar{E}$ and a short form for each experiment name and the overall grand mean is signified by $\bar{E}_{m}$. The experiments used in the vitamin $\mathrm{K}_{2}+1,25 \mathrm{D}$ meta-analyses were extracted from a single article.

Figure 5: The meta-analysis for vitamin $\mathrm{K}_{2}+1,25 \mathrm{D}$ had significantly positive overall grand mean effect sizes when comparing the combination of vitamin $\mathrm{K}_{2}+$ $1,25 \mathrm{D}$ against vitamin $\mathrm{K}_{2}$ and 1,25D.

and their CIs did not intersect zero. However, the non-directional tests indicated significance for the Mineralization group $\left(X^{2}=37.0, d f=15\right.$, $p=0.0013)$ and non-significance for the ALP Activity group $\left(X^{2}=13.6\right.$, $d f=7, p=0.059)$. This and any other discrepancy between the CI test and non-directional test are addressed in the Discussion section. Unlike the Mineralization and ALP Activity groups, the Other Experiment group had a grand mean effect size that was not significantly different than zero $\left(X^{2}=5.45, d f=5, p=0.36\right)$.

The experiments in the vitamin $\mathrm{K}_{2}$ meta-analysis were sorted into the following experiment type subgroups: Mineralization (included calcium and phosphorus levels), ALP Activity, Proliferation, DNA Levels, Osteocalcin Levels (included mRNA and protein levels) and Other Experiments (Figure 3). Most of the experiments in the vitamin $\mathrm{K}_{2}$ meta-analysis had significantly positive effect sizes, which translated to a positive and significant overall grand mean $\left(X^{2}=228\right.$, $d f=98, p<0.0001)$. A significantly positive grand mean effect was also observed for the following experiment type groups: Mineralization $\left(X^{2}=90.3, d f=29, p<0.0001\right)$, ALP $\left(X^{2}=62.0, d f=33, p=0.0016\right)$, DNA Levels $\left(X^{2=104}, d f=11, p<0.0001\right)$ and Other Experiments $\left(X^{2=34.0}\right.$ $d f=9, p<0.0001$; Figure 3$)$. This indicated that the addition of vitamin $\mathrm{K}_{2}$ significantly increased mineralization, ALP activity, DNA levels and other osteoblast parameters as compared to an untreated group. In contrast, a negative grand mean with a CI that did not intersect zero was found for the Proliferation group, which was confirmed by the results of a non-directional test being significant $\left(X^{2}=28.9, d f=10\right.$, $p=0.0013$ ). The Osteocalcin group in the vitamin $\mathrm{K}_{2}$ meta-analysis had a grand mean effect size that was not significantly different than zero $\left(X^{2}=7.09, d f=6, p=0.31\right)$.

Within the vitamin D meta-analysis, the experiments were arranged into the following experiment type subgroups: Mineralization (included calcium levels, phosphorus levels, quantification of mineral staining and mineralized volume), ALP Activity, Osteocalcin Levels (included mRNA and protein levels), Collagen Levels (included mRNA and protein levels), Osteopontin Levels (only mRNA levels) and Other Experiments (Figure 4). The overall grand mean for the vitamin D meta-analysis had a significantly positive effect size $\left(X^{2}=394, d f=128\right.$, $p<0.0001$ ), which corresponded to the majority of the effect sizes being positive and significant for the experiments. A significantly positive grand mean effect size was also observed for the Mineralization $\left(X^{2}=108\right.$, $d f=29, p<0.0001)$, ALP Activity $\left(X^{2}=55.5, d f=28, p=0.0015\right)$, Osteocalcin Levels $\left(X^{2}=79.0, d f=18, p<0.0001\right)$, Collagen Levels $\left(X^{2}=78.4, d f=31\right.$, $p<0.0001)$ and Osteopontin Levels $\left(X^{2}=42.3, d f=10, p<0.0001\right)$ groups. Conversely, the group called Other Experiments had a negative grand mean with a confidence interval that did not include zero (Figure 4). However, the non-directional test indicated that the grand mean effect was not significantly different than zero $\left(X^{2}=20.5, d f=12, p=0.057\right)$.

The experiments used in both of the $\mathrm{K}_{2}+1,25 \mathrm{D}$ meta-analyses were sorted into two subgroups: Mineralization (included calcium and phosphorus levels) and Other Experiments (Figure 5A and 5B). All of the experiments had a significantly positive effect size within the $\mathrm{K}_{2}+1,25 \mathrm{D}$ compared to $\mathrm{K}_{2}$ alone meta-analysis (Figure $5 \mathrm{~A}$ ), which corresponded to a significantly positive overall grand mean effect size $\left(X^{2}=65.3, d f=11, p<0.0001\right)$. Likewise, both the grand means were positive and significant for the Mineralization $\left(X^{2}=31.5, d f=6\right.$, $p<0.0001)$ and Other Experiments groups $\left(X^{2}=29.1, d f=5, p<0.0001\right)$. For the $\mathrm{K}_{2}+1,25 \mathrm{D}$ compared to $1,25 \mathrm{D}$ meta-analysis (Figure $5 \mathrm{~B}$ ), the majority of the experiments had effect sizes that were positive and significant. This trend agreed with the overall grand mean being positive with a confidence interval that does not include zero. However, the non-directional test was not significant, meaning that the overall grand mean might not be significantly different than zero $\left(X^{2}=18.5, d f=11, p=0.070\right)$. The Mineralization group of the $\mathrm{K}_{2}+1,25 \mathrm{D}$ compared to $1,25 \mathrm{D}$ meta-analysis had a significantly positive grand mean $\left(X^{2}=53.0, d f=6, p<0.0001\right)$, while the grand mean effect size of the Other Experiment group was not significantly different than zero $\left(X^{2}=5.99, d f=5, p=0.31\right)$. We summarized the results of the vitamin $\mathrm{K}_{1}$, $K_{2}, D$ and $K_{2}+1,25 \mathrm{D}$ meta-analyses, which were grouped by type of experiment, into. In conclusion, the addition of vitamin $\mathrm{K}_{1}, \mathrm{~K}_{2}$ and $\mathrm{D}$ to osteoblast cell cultures resulted in a significant increase to several bone cell parameters and the addition of $\mathrm{K}_{2}+1,25 \mathrm{D}$ increased mineralization within osteoblast cultures.

\section{The homogeneity within the meta-analyses grouped by cell type}

In addition to grouping the osteoblast experiments by experiment 
Citation: Lancaster CE, Harrison RE (2017) Effects of Vitamin D, $\mathrm{K}_{1}$, and $\mathrm{K}_{2}$ Supplementation on Bone Formation by Osteoblasts In Vitro: A Metaanalysis. J Biom Biostat 8: 365. doi: 10.4172/2155-6180.1000365

type, the data within the vitamin $\mathrm{K}_{2}$ and $\mathrm{D}$ meta-analyses was also categorized by the cell type utilized for the experiments (Table 2) and the homogeneity within each of these subgroups also had to be assessed. The overall grand mean for each of the vitamin meta-analyses was calculated using either the fixed or mixed-effects models, as discussed in a previous section (also in bold in Table 2). The cell type groups within both meta-analyses were heterogeneous using the fixed model and thus the grand means for each group was calculated using

\begin{tabular}{|c|c|c|c|}
\hline & $\mathbf{k}^{1}$ & $Q_{f}$ & $\mathbf{Q}_{\mathrm{m}}{ }^{2}$ \\
\hline Vitamin $\mathrm{K}_{2}$ & 98 & $567^{*}$ & $168^{*}$ \\
\hline Murine Cell Line & 29 & $139^{*}$ & $34.8 \mathrm{NS}$ \\
\hline Human Cell Line & 15 & $139^{*}$ & $26.6^{*}$ \\
\hline Murine Primary Cells & 19 & $57.4^{*}$ & $18.0 \mathrm{NS}$ \\
\hline Human Primary Cells & 35 & $213^{*}$ & $52.5^{*}$ \\
\hline Vitamin D & 128 & $652^{*}$ & $311^{*}$ \\
\hline Murine Cell Line & 36 & $131^{*}$ & $62.7^{*}$ \\
\hline Human Cell Line & 34 & $125^{*}$ & $65.0^{*}$ \\
\hline Murine Primary Cells & 14 & $44.8^{*}$ & $20.7 \mathrm{NS}$ \\
\hline Human Primary Cells & 44 & $241^{*}$ & $93.5^{*}$ \\
\hline
\end{tabular}

${ }^{1}$ Cochran's $Q$ tests were used to determine the homogeneity of the treatment responses from $\mathrm{k}$ \# of experiments.

${ }^{*} p<0.050$ indicates responses are heterogeneous and NS (no significance) indicates responses are homogeneous.

${ }^{2}$ The homogeneity of the mixed-effects model was only determined if the fixedeffects model was considered heterogeneous $(p<0.050)$.

Table 2: The fixed-effects $\left(Q_{f}\right)$ and mixed-effects $\left(Q_{m}\right)$ models' homogeneity test results of each vitamin meta-analysis, where the meta-analyses are grouped by cell type. the mixed model. In the vitamin $\mathrm{K}_{2}$ meta-analysis, both murine groups were homogenous, while the human groups were heterogeneous using the mixed-effect model. Only the Murine Primary Cells group within the vitamin D meta-analysis was homogeneous using the mixed-effects model, while the rest of the groups were heterogeneous.

Cell type grouped vitamin $\mathrm{K}_{2}$ and $\mathrm{D}$ meta-analyses had overall grand mean effect sizes that were greater than zero and most of the cell type grand mean effect sizes were significantly positive.

Within the graphical representations of the meta-analyses classified by cell type (Figures 6 and 7), each unlabelled bar represents a single experiment from one paper and its effect size indicated if the vitamin changed a measurement of osteoblast maturation compared to an untreated group. The overall grand mean effect size (bar labelled $\bar{E}_{m}$ in Figures 6 and 7) for each meta-analysis was the same information that was displayed in the experiment type grouped graphs for vitamin $\mathrm{K}_{2}$ and $\mathrm{D}$ (Figures 3 and 4, respectively). The experiments were shadecoded according to what cell type was assayed and the grand means for each of the cell type subgroups was utilized to determine if the vitamin affected osteoblast maturation parameters differently in various cell types (bars labelled $\bar{E}$ and a short form for each cell type name in Figures 6 and 7).

The experiments in the vitamin $\mathrm{K}_{2}$ meta-analysis were also sorted into the following cell type subgroups: Murine Cell Line, Human Cell Line, Murine Primary Cells and Human Primary Cells (Figure 6). As previously stated, the overall grand mean effect size for the vitamin $\mathrm{K}_{2}$ meta-analysis was positive and significant. The cell type grand means

\section{Vitamin $\mathrm{K}_{2}$ Meta-analysis Subanalysis: Cell Type}

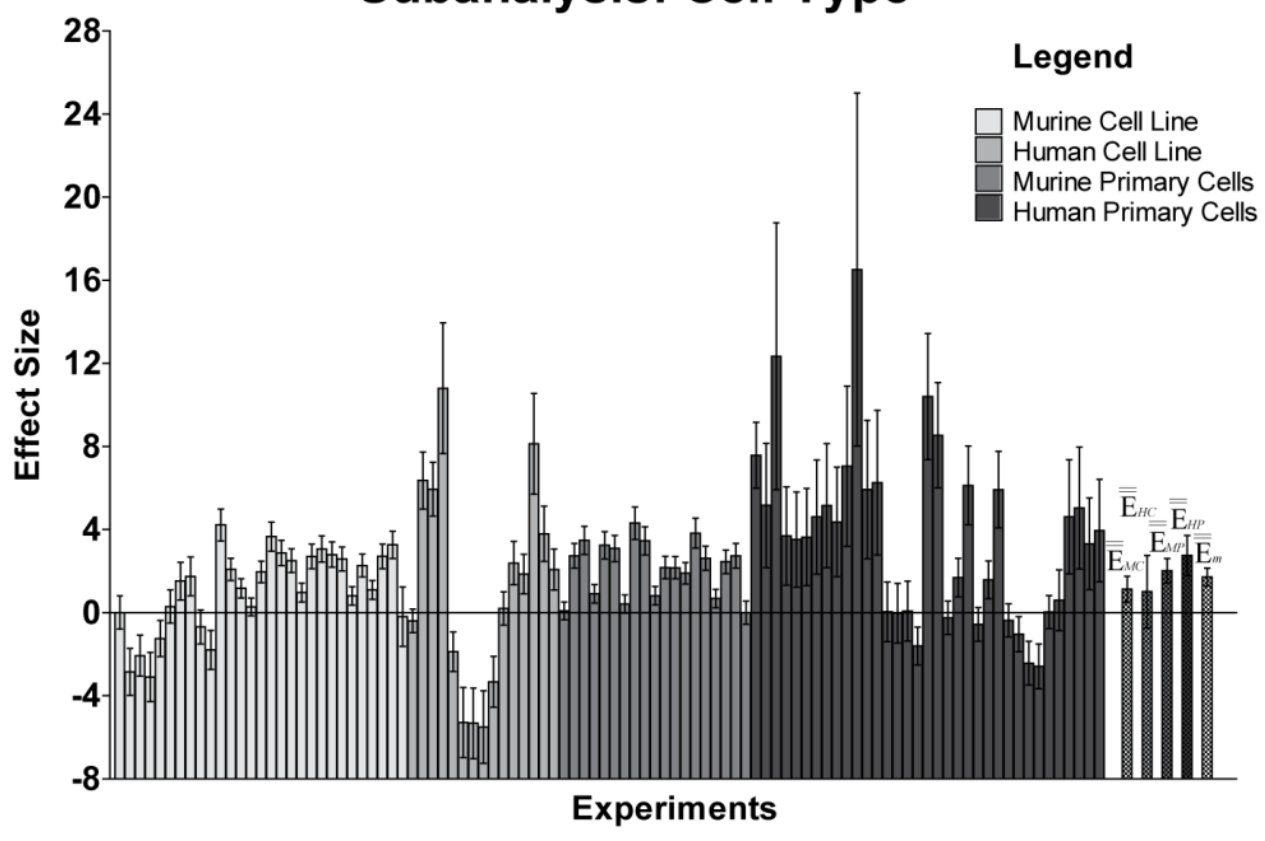

In the graph displaying the vitamin $\mathrm{K}_{2}$ meta-analysis that was grouped by cell type, each unlabelled bar represents the effect size of an experiment, as measured using the Hedges' $d$ method. The bars were shaded according to cell type and the error bars represent $95 \%$ confidence intervals. The grand means for each cell type is signified by $\bar{E}$ and a short form for each cell type name and the overall grand mean is signified by $\bar{E}_{m}$. The experiments used in the vitamin $\mathrm{K}_{2}$ metaanalysis were extracted from 8 articles.

Figure 6: The vitamin $\mathrm{K}_{2}$ meta-analysis had an overall grand mean effect size that was significantly greater than zero and most of the cell type grand mean effect sizes were significantly positive. 


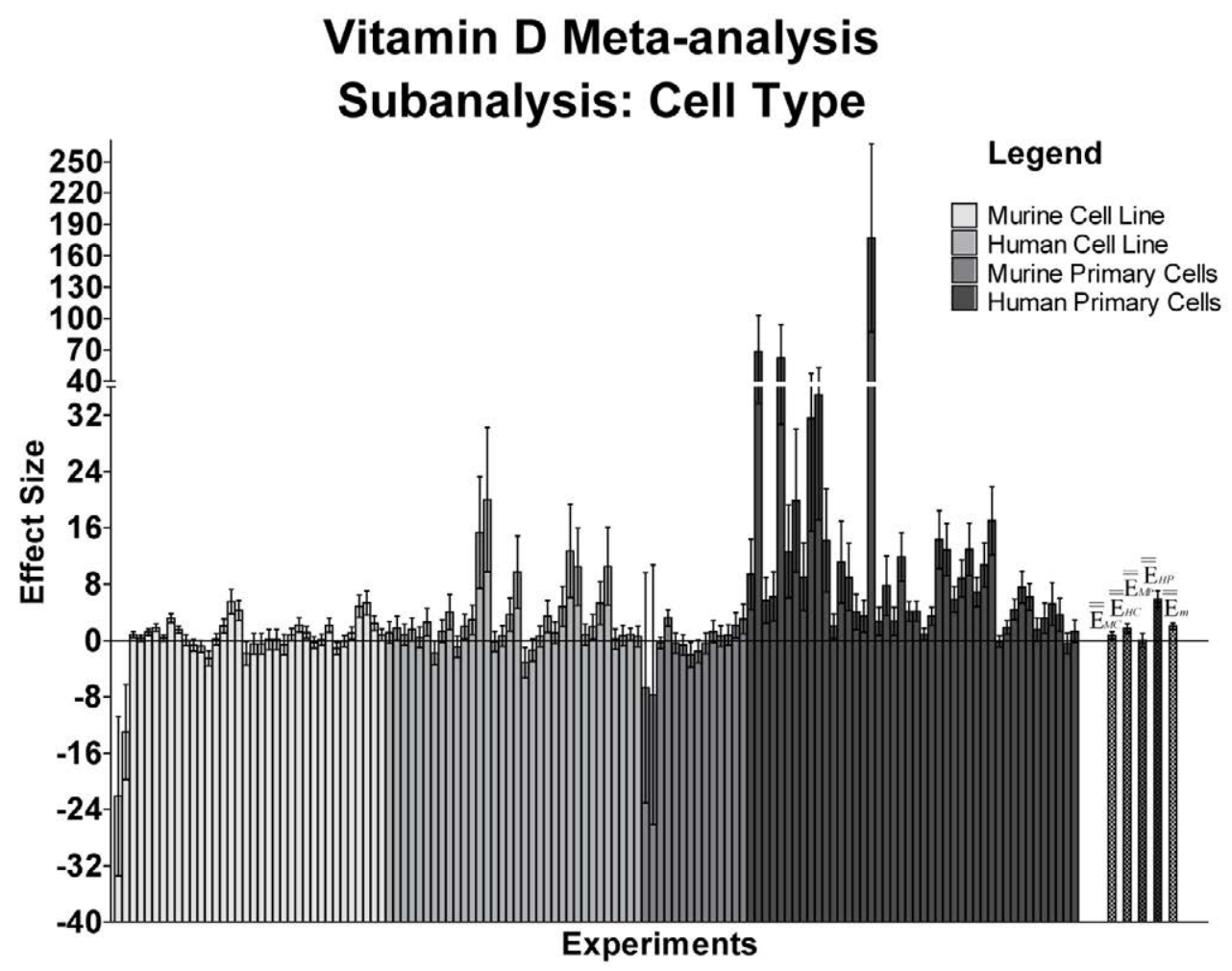

In the graph displaying the vitamin D meta-analysis that was grouped by cell type, each unlabelled bar represents the effect size of an experiment, as measured using the Hedges' $d$ method. The bars were shaded according to cell type and the error bars represent $95 \%$ confidence intervals. The grand means for each cell type is signified by $\bar{E}$ and a short form for each cell type name and the overall grand mean is signified by $\bar{E}_{m}$. The experiments used in the vitamin $\mathrm{D}$ metaanalysis were extracted from 15 articles.

Figure 7: The vitamin D meta-analysis revealed a significantly positive overall grand mean effect size and the majority of the cell type grand means were significantly greater than zero.

for the following groups were significantly positive: Murine Cell Line $\left(X^{2}=47.7, d f=29, p=0.016\right)$, Murine Primary Cells $\left(X^{2=62.5}, d f=19\right.$, $p<0.0001)$ and Human Primary Cells $\left(X^{2=84.1}, d f=35, p<0.0001\right)$. The Human Cell Line group had a grand mean that was not significantly different than zero based on the confidence interval test, but was

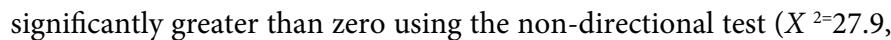
$d f=15, p=0.022$; Figure 6). This suggests that the addition of vitamin $\mathrm{K}_{2}$ to human osteoblast cell line do not change maturation characteristics as compared to an untreated control.

Within the vitamin $\mathrm{D}$ meta-analysis, the experiments were also grouped into the following cell type subgroups: Murine Cell Line, Human Cell Line, Murine Primary Cells and Human Primary Cells (Figure 7). The overall grand mean effect for the vitamin D metaanalysis was significantly positive, as mentioned earlier. Significantly positive grand means were obtained for the Murine Cell Line $\left(X^{2=} 69.7\right.$, $d f=36, p=0.0006)$, Human Cell Line $\left(X^{2=85.6}, d f=34, p<0.0001\right)$ and Human Primary Cells $\left(X^{2=189}, d f=44, p<0.0001\right)$ groups. However, the grand mean effect size of the group called Murine Primary Cells was not significantly different than zero $\left(X^{2=20.7}, d f=14, p=0.11\right.$; Figure 7$)$. The results of the vitamin $\mathrm{K}_{2}$ and $\mathrm{D}$ meta-analyses that were grouped by cell type were summarized. Altogether this analysis indicates that the addition of vitamin D to murine and human osteoblast cell lines, as well as human primary osteoblasts, increases osteoblast maturation/bone formation parameters, while vitamin $\mathrm{K}_{2}$ supplementation enhances osteoblast maturation parameters in murine cell lines, murine primary cells and human primary cells.

\section{Discussion and Conclusion}

Our work represents the first cell biology meta-analysis of the effects of vitamin supplementation on parameters related to bone formation. The experiment type grouped meta-analyses revealed that the addition of vitamin $\mathrm{K}_{1}, \mathrm{~K}_{2}$ or $\mathrm{D}$ to osteoblasts resulted in increased mineralization within the culture. Enhanced mineralization was also observed for the combination of vitamin $\mathrm{K}_{2}+1,25 \mathrm{D}$ against both of the singular vitamin controls. ALP activity significantly increased with vitamin $\mathrm{K}_{2}$ or vitamin $\mathrm{D}$ addition, but the effects of vitamin $\mathrm{K}_{1}$ supplementation were inconclusive given that the confidence interval and non-directional tests did not agree. The levels of osteocalcin increased with the addition of vitamin $\mathrm{D}$, but did not change when vitamin $\mathrm{K}_{2}$ was supplemented. Surprisingly, vitamin $K_{2}$ addition increased the DNA levels within the culture, but significantly decreased the amount of proliferation within the culture. Supplementation with vitamin D also resulted in increased collagen and osteopontin production by osteoblasts. The addition of vitamin $\mathrm{K}_{2}$ significantly increased the bone formation parameters measured in the group called Other Experiments, but vitamin $\mathrm{K}_{1}$ supplementation had no effect and vitamin $\mathrm{D}$ addition had inconclusive effects on the osteoblast maturation characteristics in the Other Experiments group. Interestingly, the effect of the combination of vitamin $\mathrm{K}_{2}+1,25 \mathrm{D}$ supplementation compared to the effect of vitamin $\mathrm{K}_{2}$ addition alone resulted in increased bone formation characteristics in the Other Experiments group, but not when compared to the effects of $1,25 \mathrm{D}$ addition alone. The lack of consistency amongst the meta-analyses concerning the Other Experiments group could be 
because there were a variety of experiments delegated to this group for each meta-analysis. Altogether this indicated that the addition of vitamin $\mathrm{K}_{1}, \mathrm{~K}_{2}$ and $\mathrm{D}$ as well as the combination of vitamin $\mathrm{K}_{2}+1,25 \mathrm{D}$ increases bone mineralization within osteoblast cultures, but might not consistently increase all of the other osteoblast maturation parameters that are thought to be indicative of bone formation.

The cell type categorized meta-analyses revealed that both vitamin $\mathrm{K}_{2}$ and vitamin $\mathrm{D}$ supplementation increased bone cell parameters in murine osteoblast cell lines and human primary osteoblasts. In addition, only supplementation of vitamin $\mathrm{K}_{2}$ resulted in an increase in maturation parameters in murine primary osteoblast cell cultures, while vitamin D addition had no effect. In human osteoblast cell lines, vitamin $\mathrm{D}$ addition increased bone formation measurements, but vitamin $\mathrm{K}_{2}$ supplementation had inconclusive effects. In summary, addition of vitamin $\mathrm{K}_{2}$ or $\mathrm{D}$ has variable effects on bone cell parameters depending on cell type tested.

The vitamin $\mathrm{K}_{2}$ meta-analysis revealed that the addition of vitamin $\mathrm{K}_{2}$ to osteoblasts decreased proliferation. Since the first stage of osteoblast maturation is the proliferative phase [39], this suggests that vitamin $\mathrm{K}_{2}$ addition impairs osteoblast maturation. However, decreased human primary osteoblast proliferation after a week of $1,25 \mathrm{D}$ supplementation has also been linked with increased late stage mineralization [32]. The addition of $1,25 \mathrm{D}$ may prolong the time spent in the differentiation and mineralization phases, which explains the increased mineralization in the supplemented cultures as compared to the untreated cultures. However, our vitamin $\mathrm{K}_{2}$ meta-analysis also revealed that vitamin $\mathrm{K}_{2}$ supplementation increased DNA levels, which is another indicator of cell proliferation. This contradictory data suggests that these experimental assays should be more closely analyzed to determine their predictive value in measuring osteoblast maturation.

Homogeneity of the experiments within a subgroup of the metaanalysis will increase the confidence that the grand mean effect size will represent any study looking at the same phenomenon under the same conditions (i.e. same cell type). Some of the subgroups that were analyzed within these meta-analyses were heterogeneous and thus one cannot be completely certain that the results seen will represent every vitamin supplementation cell biology paper. Ultimately it would be ideal to continue further subanalysis of all of the heterogeneous subgroups until each group is homogeneous. However, further subanalysis on all of the subgroups was not possible with the already small number of experiments in some of the groups.

Both the confidence interval (CI) test and the non-directional test were used to assess if the grand mean effect sizes were significantly different than zero. However, there were times within the metaanalyses when the results of the confidence interval test did not agree with that of the non-directional test. The non-directional test is more conservative than the $\mathrm{CI}$ test and is therefore more likely to result in nonsignificance when the sample size is small and the variance is large [40]. Simultaneously, the confidence interval test is more affected by outliers than the robust non-directional test [41] and could lead to nonsignificance when there are outliers present. Altogether, this could indicate why the results of both statistical tests did not agree with each other in every scenario. In the cases where the tests do not agree, the effect sizes could still be significantly different than zero. Therefore the definition of a significant result within meta-analyses in general might need to be re-evaluated [40].

A species specific effect of $1,25 \mathrm{D}$ on mineralization was observed in past literature, where 1,25D supplementation resulted in increased mineralization in human osteoblast cultures [17,32,35,42,43], but had primarily negative effects on mineralization in the mouse MC3T3 cell line $[25,44]$. In addition, the supplementation of $1,25 \mathrm{D}$ to mice resulted in increased levels of pyrophosphate and therefore decreased mineralization of bones within the mouse [45], as there needs to be low pyrophosphate levels for mineralization to occur in vitro and within the body [46]. Increased pyrophosphate levels also leads to adverse effects within cell culture, including autophagic cell death observed in inorganic pyrophosphatase-mutated yeast cells under fermentative conditions [47]. Altogether, this could help explain why vitamin D addition had differential effects on osteoblast maturation parameters in murine or human osteoblasts.

Clinical meta-analyses have previously revealed that supplementation with vitamin D and vitamin $\mathrm{K}$ resulted in increased bone mineral density at the femoral neck and lumbar spine, respectively [48], which agrees with the significant increase in mineralization we observed using supplementation with vitamin D and K. Similar to our meta-analyses, the results of both of these studies must be treated with caution due to heterogeneity. However, we observed variable results of the effects of these vitamins on parameters indicative of bone formation depending on the type of cells used, which calls into question the use of particular cell lines and animal models to test drugs/supplements as a precursor to clinical studies.

Although there have been widespread publications on the effect of vitamin $\mathrm{D}, \mathrm{K}_{1}$ and $\mathrm{K}_{2}$ supplementation on bone formation, a definite conclusion concerning their effect in vitro on cell lines or primary cells has yet to be made. We found through performing meta-analyses of the previous literature that the addition of vitamin $\mathrm{K}_{1}, \mathrm{~K}_{2}$ or $\mathrm{D}$, as well as the addition of $\mathrm{K}_{2}+1,25 \mathrm{D}$, to osteoblasts increased bone mineralization, but did not consistently change all of the osteoblast maturation parameters that are associated with bone formation. When the experiments were grouped by cell type, it was revealed that vitamin $\mathrm{K}_{2}$ or D supplementation had variable effects on bone cell parameters within cultures of different cell types. Ultimately, this work indicates that the conditions in which bone formation is studied must be considered carefully to determine the effect of vitamin $\mathrm{K}_{1}$, vitamin $\mathrm{K}_{2}$ and vitamin $\mathrm{D}$ supplementation on osteoblasts in vitro. In addition, meta-analysis is an extremely useful tool that has yet to be fully utilized in the field of cell biology.

\section{Acknowledgement}

We would like to thank Dr. Marc Cadotte for sharing his statistical expertise and for the critical reading of this manuscript. This study was supported by a Natural Science and Engineering Research Council grant (RGPIN 298538-09) and a MOP-68992 grant from the Canadian Institutes of Health Research to R.E.H.

\section{References}

1. Long $F$ (2012) Building strong bones molecular regulation of the osteoblas lineage. Nature Reviews Molecular Cell Biology 13: 27-38.

2. Whitson SW (1984) fetal bovine bone cells synthesize bone specific matrix proteins. The Journal of Cell Biology 99: 607-614.

3. Whitson SW, Whitson MA, Bowers DE, Falk MC (1992) Factors influencing synthesis and mineralization of bone matrix from fetal bovine bone cells grown in vitro. Journal of Bone and Mineral Research the Official Journal of the American Society for Bone and Mineral Research 7: 727-741.

4. Pustylnik S, Fiorino C, Nabavi N, Zappitelli T, Da Silva R, et al. (2013) EB1 levels are elevated in ascorbic acid (AA) stimulated osteoblasts and mediate cell-cell adhesion-induced osteoblast differentiation. Journal of Biological Chemistry 288: 26-110.

5. Beck GR (2003) Inorganic phosphate as a signaling molecule in osteoblast differentiation. Journal of Cellular Biochemistry 90: 234-243.

6. Bikle DD (2012) Vitamin D and bone. Current Osteoporosis Reports 10: 15-19 
Citation: Lancaster CE, Harrison RE (2017) Effects of Vitamin D, $\mathrm{K}_{1}$, and $\mathrm{K}_{2}$ Supplementation on Bone Formation by Osteoblasts In Vitro: A Metaanalysis. J Biom Biostat 8: 365. doi: 10.4172/2155-6180.1000365

7. Stephensen CB, Zerofsky M, Burnett DJ, Lin Y-p, Hammock BD, et al. (2012) Ergocalciferol from Mushrooms or Supplements Consumed with a Standard Meal Increases 25 Hydroxyergocalciferol but Decreases 25 Hydroxycholecalciferol in the Serum of Healthy Adults. Journal of Nutrition 142 1246-1252.

8. Jones G, Strugnell SA, DeLuca HF (1998) Current understanding of the molecular actions of vitamin D Physiological Reviews 78: 1193-1231.

9. Jensen MB (2014) Vitamin D and male reproduction. Nature Reviews Endocrinology Nature Publishing Group. 10: 175-186.

10. Hamidi MS, Gajic-Veljanoski O, Cheung AM (2013) Vitamin K and bone health Journal of Clinical Densitometry. The Official Journal of the International Society for Clinical Densitometry 16: 409-413.

11. Nakagawa K, Hirota Y, Sawada N, Yuge N, Watanabe M, et al. (2010) Identification of UBIAD1 as a novel human menaquinone 4 biosynthetic enzyme. Nature Nature Publishing Group. 468: 117-221.

12. Haidich AB (2010) Meta-analysis in medical research. Hippokratia 14: 29-37.

13. Garg AX, Hackam D, Tonelli M (2008) Systematic review and meta-analysis: When one study is just not enough. Clinical Journal of the American Society of Nephrology 3: 253-260

14. Stewart G (2010) Meta-analysis in applied ecology. Biology Letters 6: 78-81

15. Atkins GJ, Welldon KJ, Wijenayaka AR, Bonewald LF, Findlay DM (2009) Vitamin $\mathrm{K}$ promotes mineralization osteoblast to osteocyte transition and an anticatabolic phenotype by $\mathrm{y}$ carboxylation dependent and independen mechanisms. American Journal of Physiology Cell Physiology 297: 1358-1367.

16. Koshihara $Y$, Hoshi K, Ishibashi H, Shiraki M (1996) Vitamin K2 promotes 1alpha $25(\mathrm{OH}) 2$ vitamin D3 induced mineralization in human periosteal osteoblasts. Calcified Tissue International 59: 466-573.

17. Koshihara Y, Hoshi K, Okawara R, Ishibashi H, Yamamoto S (2003) Vitamin K stimulates osteoblastogenesis and inhibits osteoclastogenesis in human bone marrow cell culture. The Journal of Endocrinology 176: 339-348.

18. Gigante A, Torcianti M, Boldrini E, Manzotti S, Falcone G, et al. (2008) Vitamin $\mathrm{K}$ and $\mathrm{D}$ association stimulates in vitro osteoblast differentiation of fracture site derived human mesenchymal stem cells. Journal of Biological Regulators and Homeostatic Agents 22: 35-44.

19. Notoya K, Yoshida K, Shirakawa Y, Taketomi S, Tsuda M (1995) Similarities and differences between the effects of ipriflavone and vitamin $\mathrm{K}$ on bone resorption and formation in vitro Bone 16: 349-353.

20. Urayama S, Kawakami A, Nakashima T, Tsuboi M, Yamasaki S, et al. (2000) Effect of vitamin K2 on osteoblast apoptosis Vitamin K2 inhibits apoptotic cell death of human osteoblasts induced by Fas proteasome inhibitor etoposide and staurosporine. Journal of Laboratory and Clinical Medicine 136: 181-193.

21. Akedo Y, Hosoi T, Inoue S, Ikegami A, Mizuno Y, et al. (1992) Vitamin K2 modulates proliferation and function of osteoblastic cells in vitro. Biochemical and Biophysical Research Communications 187: 814-820.

22. Yamaguchi M, Sugimoto E, Hachiya S (2001) Stimulatory effect of menaquinone 7 (vitamin K2) on osteoblastic bone formation in vitro. Molecular and Cellular Biochemistry 223: 131-137.

23. Iwamoto I, Kosha S, Fujino T, Nagata Y (2002) Effects of Vitamin K2 on Bone of Ovariectomized Rats and on a Rat Osteoblastic Cell Line. Gynecologic and Obstetric Investigation 53: 144-148.

24. Yamaguchi M, Weitzmann MN (2012) High dose 125(OH) $2 D 3$ inhibits osteoblast mineralization in vitro. International Journal of Molecular Medicine 29: 934-938.

25. Chen J, Dosier CR, Park JH, De S, Guldberg RE, et al. (2013) Mineralization of three-dimensional osteoblast cultures is enhanced by the interaction of $1 \alpha$, 25-dihydroxyvitamin D3 and BMP2 via two specific vitamin D receptors. Journal of Tissue Engineering and Regenerative Medicine 25.

26. Sato F, Ouchi Y, Okamoto Y, Kaneki M, Nakamura T, et al. (1991) Effects of vitamin D2 analogs on calcium metabolism in vitamin D-deficient rats and in MC3T3-E1 osteoblastic cells. Research in Experimental Medicine 191: 235-242.

27. Matsumoto T, Igarashi C, Takeuchi Y, Harada S, Kikuchi T, et al. (1991) Stimulation by 125 -Dihydroxyvitamin D3 of in vitro mineralization induced by osteoblast-like MC3T3-E1 cells. Bone 12: 27-32.

28. Widaa A, Brennan O, O'Gorman DM, O'Brien FJ (2014) The osteogenic potential of the marine derived multi-mineral formula aquamin is enhanced by the presence of vitamin D. Phytotherapy Research 28: 678-684.

29. Narayanan R, Smith C, Weigel N (2002) Vector-averaged gravity-induced changes in cell signaling and vitamin d receptor activity in MG-63 cells are reversed by a 1,25-(OH)2D3 analog, EB1089. Bone 31: 381-388.

30. Franceschi RT, Romano PR, Park KY (1988) Regulation of type I collagen synthesis by 1,25 -dihydroxyvitamin D3 in human osteosarcoma cells. The Journal of Biological Chemistry 263: 18-25.

31. Atkins GJ, Anderson PH, Findlay DM, Welldon KJ, Vincent C, et al. (2007) Metabolism of vitamin D3 in human osteoblasts evidence for autocrine and paracrine activities of 1 alpha 25-dihydroxyvitamin D3 Bone 40: 1517-1528.

32. Kunisada T, Kawai A, Inoue H, Namba M (1997) Effects of simulated microgravity on human osteoblast-like cells in culture. Acta Medica Okayama 51: 135-140.

33. Adluri RS, Zhan L, Bagchi M, Maulik N, Maulik G (2010) Comparative effects of a novel plant-based calcium supplement with two common calcium salts on proliferation and mineralization in human osteoblast cells. Molecular and Cellular Biochemistry 340: 73-80.

34. Zhou S, Glowacki J, Kim SW, Hahne J, Geng S, et al. (2012) Clinical characteristics influence in vitro action of 1,25-dihydroxyvitamin $\mathrm{D}(3)$ in human marrow stromal cells. Journal of Bone and Mineral Research the Official Journal of the American Society for Bone and Mineral Research 27: 1992-2000.

35. Kumei Y, Morita S, Nakamura H, Katano H, Ohya K, et al. (2004) Osteoblas responsiveness to 1alpha 25-dihydroxyvitamin D3 during spaceflight. Annals of the New York Academy of Sciences 1030: 121-124.

36. Lynch MP, Stein JL, Stein GS, Lian JB (1995) the influence of type I collagen on the development and maintenance of the osteoblast phenotype in primary and passaged rat calvarial osteoblasts modification of expression of genes supporting cell growth adhesion and extracellular matrix mineralization. Experimental Cell Research 216: 35-45.

37. Gurevitch J, Curtis PSS, Jones MHH (2001) Meta-analysis in ecology. Advances in Ecological Research 32: 199-247.

38. Neve A, Corrado A, Cantatore FP (2011) Osteoblast physiology in normal and pathological conditions. Cell and Tissue Research 343: 289-302.

39. Cadotte MW (2006) Dispersal and Species Diversity A Meta-Analysis. The American Naturalist 167: 913-924.

40. McHugh ML (2013) The Chi-square tests of independence. Biochemia Medica 23: $143-149$.

41. Van Driel M, Koedam M, Buurman CJ, Roelse M, Weyts F, et al. (2006) Evidence that both 1alpha, 25-dihydroxyvitamin D3 and 24-hydroxylated D3 enhance human osteoblast differentiation and mineralization. Journal of Cellular Biochemistry 99: 922-935.

42. Woeckel VJ, Alves RDAM, Swagemakers SMA, Eijken M, Chiba $\mathrm{H}$ et al. (2010) 1Alpha, 25- $(\mathrm{OH}) 2 \mathrm{D} 3$ acts in the early phase of osteoblast differentiation to enhance mineralization via accelerated production of mature matrix vesicles. Journal of Cellular Physiology 225: 593-600.

43. Shi YC, Worton L, Esteban L, Baldock P, Fong C, et al. (2007) Effects of continuous activation of vitamin $D$ and Want response pathways on osteoblastic proliferation and differentiation. Bone 41: 87-96.

44. Lieben L, Masuyama R, Torrekens S, Van Looveren R, Schrooten J, et al (2012) Normocalcemia is maintained in mice under conditions of calcium malabsorption by vitamin D-induced inhibition of bone mineralization. Journal of Clinical Investigation 122: 1803-1815.

45. Russell RG, Bisaz S, Donath A, Morgan DB, Fleisch H (1971) Inorganic pyrophosphate in plasma in normal persons and in patients with hypophosphatasia, osteogenesis imperfecta, and other disorders of bone. Journal of Clinical Investigation 50: 961-979.

46. Serrano-Bueno G, Hernández A, López-Lluch G, Pérez-Castiñeira JR, Navas $P$, et al. (2013) Inorganic pyrophosphatase defects lead to cell cycle arrest and autophagic cell death through NAD+ depletion in fermenting yeast. Journal of Biological Chemistry 288: 13-92.

47. Reid IR, Bolland MJ, Grey A (2014) Effects of vitamin D supplements on bone mineral density A systematic review and meta-Analysis. The Lancet Elsevier Ltd. 383: 146-155.

48. Fang Y, Hu C, Tao X, Wan Y, Tao F (2012) Effect of vitamin K on bone mineral density a meta-analysis of randomized controlled trials. Journal of Bone and Mineral Metabolism 30: 60-68. 